\title{
Os impactos e mudanças promovidos pela avaliação institucional no ensino de graduação das instituições de ensino superior fundacionais municipais catarinenses sob influência do Programa de Avaliação Institucional das Universidades Brasileiras - PAIUB
}

Argos Gumbowsky

Resumo: O artigo tem como objetivo principal apresentar os impactos e mudanças promovidas pela avaliação institucional nas condições de produção do ensino de graduação das Instituições de Ensino Superior Fundacionais Municipais Catarinenses - IESFMC. O lançamento do Paiub constituiu-se na gênese do processo de avaliação institucional no cenário das IESFMC, pois até então as mesmas não possuíam nenhum programa institucionalizado de avaliação. Nesse sentido, o primeiro Seminário Catarinense de Avaliação Institucional realizado pela Acafe em 1994 pode ser considerado como marco das discussões sobre a temática no contexto das IES. Utilizou da pesquisa de campo e bibliográfica. Concluiu-se que apesar dos diferentes estágios do Programa de Avaliação Institucional das Universidades Brasileiras - Paiub implementados pelas Instituições de Ensino Superior, quando da sua vigência foi possível verificar impactos e mudanças nas condições de produção do ensino de graduação.

Palavras-chave: Avaliação institucional. Universidades municipais. PAIUB.

The impacts and changes promoted by institutional avaliation in the teaching for graduation of foundational county and catarinense higher education under influence of Programme of Institutional Avaliation in the Brazilian Universities - PAIUB

Abstract: This article has as main aim shows the impacts and changes promoted by Intitutional Avaliation in conditions of production in the teaching for graduation in Institutions of Foundational County and Catarinense Higher Education - IESFMC. The launch of Paiub constitutes the genesis of process in the Institutional Avaliation in the scene from IESFMC, so until that they have never had no one institutionalized programme of avaliation. This way, the first Catarinense seminar of Institutional Avaliation made by Acafe in 1994, can be considered as a landmark of discussions about the issue in the context of IES. This utilized field and bibliographical research. It was concluded that in despite of different stages from Programme of Institutional Avaliation of Brazilian Universities - Paiub implemented by Intitutions of Higher Education, when it was established was possible to check impacts and changes in the conditions in Higher Teaching.

Key words: Institutional avaliation. County universities. PAIUB. 
Os impactos e mudanças promovidos pela avaliação institucional no ensino de graduação das instituições de ensino superior fundacionais municipais catarinenses sob influência do Programa de Avaliação Institucional das Universidades Brasileiras - PAIUB.

\section{Introdução}

O Estado de Santa Catarina apresenta, no contexto do ensino superior brasileiro, uma situação particular. Criou-se nas décadas de 1960 e 1970 um modelo de ensino superior com características singulares, ou seja, instituições criadas pela iniciativa do poder público municipal constituindo o Sistema Estadual de Educação, com forte compromisso de promover o desenvolvimento regional. A partir da década de 1980 muitas das instituições isoladas passaram à condição de Universidades.

As primeiras iniciativas no campo da avaliação institucional remontam à década de 1990 quando do lançamento do Programa de Avaliação Institucional das Universidades Brasileiras - Paiub.

O presente artigo resultou de estudo que pretendeu conhecer os impactos e mudanças promovidos pela avaliação institucional nas condições de produção do ensino de graduação das Instituições de Ensino Superior Fundacionais Municipais Catarinenses - IESFMC sob influência do Paiub.

As IES pesquisadas foram as seguintes: Universidade do Vale do Itajaí - Univali; Universidade Regional de Blumenau - Furb; Universidade do Sul de Santa Catarina - Unisul; Universidade do Extremo-Sul Catarinense - Unesc; Universidade da Região de Joinville Univille; Universidade do Oeste de Santa Catarina - Unoesc; Universidade do Contestado UnC; Universidade do Planalto Catarinense - Uniplac; Universidade do Vale do Itajaí - Unidavi; Centro Universitário de Jaraguá do Sul - Unerj; Centro Universitário de Brusque - Cesbe. As IES, para fins de relatório de pesquisa, foram identificadas como UNI-01 a UNI-11.

A coleta de dados ocorreu através de visita a cada IESFMC e culminando com entrevistas. Para a estruturação da mesma, tomou-se como referência estudos desenvolvidos por Leite (2000), Freitas e Silveira (1997) entre outros. A entrevista consistiu num misto entre a modalidade estruturada ou padronizada e modalidade semiestruturada, no momento em que se buscou informações junto aos Coordenadores de Avaliação Institucional - CPAI e PróReitores de Ensino de Graduação - Proen. Além das CPAI, foram entrevistados o Assessor para Avaliação Institucional da Associação Catarinense das Fundações Educacionais - Acafe e o Presidente do Conselho Estadual de Educação de Santa Catarina. Totalizou, assim, a população de vinte e quatro entrevistados. As informações obtidas por meio desses instrumentos foram complementadas com outros documentos fornecidos por ocasião da visita, tais como, relatórios, artigos produzidos, resumos, etc.

O estudo teve como categorias norteadoras: avaliação X impacto X mudança. Para a definição das categorias de análise, recorreu-se a pesquisadores cujos estudos, em algum momento, contemplaram as mesmas. A categoria avaliação era, na percepção de Dias Sobrinho $(1995$, p. 33) a

[...] categoria imprescindível para a produção contínua da Universidade. Faz-se necessário que a universidade saiba, de forma permanente e integrada os valores dominantes no ensino, na pesquisa, na extensão e na gestão. O conhecimento desses valores permite que a universidade rediscuta seu projeto, suas prioridades e as relações com a comunidade interna e externa.

Para Hollister, Kemper e Wooldridge (1995 apud Leite, 2000, p.88) 
[...] a avaliação do impacto pergunta se o programa é, no geral, um êxito ou um fracasso e resulta tipicamente quantitativa por seu enfoque. Em contraste, a análise de processo, se pergunta como funciona o programa, insistindo em identificar modos de melhorar as operações e o desenho do programa e resulta tipicamente qualitativa por seu enfoque (apud LEITE, 2000, p. 89).

Leite (2000) descreve as categorias avaliação, impacto e mudança entendendo que avaliação consistiu no "processo desenvolvido pelas I.E.S. brasileiras dentro da metodologia Paiub, que compreendeu as seguintes fases - sensibilização, diagnóstico, avaliação interna e avaliação externa"; impacto consistiu "no resultado imediato do processo avaliativo" e mudança consistiu na "concretização dos impactos através de medidas que interferem a médio e longo prazo na instituição" (p. 94).

Muito embora a pesquisa tenha sido desenvolvida na primeira década deste século, julga-se pertinente a divulgação dos resultados, considerando o reduzido número de produções acerca do Paiub. Outro fator reside nas contradições das políticas avaliativas desenvolvidas quase vinte e cinco anos após seu lançamento e cujas perspectivas indicam maior centralização, o controle, a punição contrariando os princípios do Paiub, de uma avalição processual e colegiada. O estudo poderá auxiliar pesquisadores que não vivenciaram esta rica fase do processo de Avaliação Institucional no Brasil.

\section{Desenvolvimento}

\subsection{O Programa de Avaliação Institucional da Universidades Brasileiras - Paiub}

No mês de dezembro de 1993 foi oficialmente criado o Programa de Avaliação Institucional das Universidades Brasileiras - Paiub. O Programa constituiu-se numa atitude antecipatória ao Estado na implementação de processos de avaliação e foi uma construção coletiva.

O PAIUB foi inspirado em experiências de vários outros países e, pela abrangência dos seus indicadores, pelos princípios pedagógicos-filosóficos que o norteiam e pela metodologia clara e coerente que adota, supera em muito, no mérito e na forma, a ingenuidade do Provão. Mais de $70 \%$ das universidades brasileiras estão hoje envolvidas com o PAIUB, com resultados animadores em várias regiões do país. Infelizmente, enquanto a UNESCO dedicava um número inteiro de sua revista 'Educacion Superior Y Sociedad'ao PAIUB, o MEC de Paulo Renato, mostrando injustificável descaso para com o trabalho de seu antecessor, criava a SEDIAE, uma espécie de Secretaria Especial para os provões de todos os graus (RISTOFF, 1999, p. 223).

Teve o grande mérito de constituir-se numa alternativa aos programas gestados pelo Estado Avaliativo consorciado com a política neoliberal, na medida em que nele

não há competitividade entre instituições ou pessoas. Se, de um ponto de vista neoliberal, busca-se avaliar produtos e coisas com o objetivo de 'rankear', o Paiub é o oposto disso e supera essa visão mercantilista. Aglutina as Universidades em torno de um processo que visa a melhoria de todas sem competir, excluir ou punir. (MARCHI, 1996, p. 53).

Para Sinder (1998), "O PAIUB, como um programa de avaliação dos cursos de graduação, representa o segundo momento mais importante da discussão acerca da avaliação institucional da universidade brasileira, se considerarmos o relatório do GERES como sendo o primeiro." (p. 152). Dias Sobrinho (2000) considerava que "as duas características fundamen- 
Os impactos e mudanças promovidos pela avaliação institucional no ensino de graduação das instituições de ensino superior fundacionais municipais catarinenses sob influência do Programa de Avaliação Institucional das Universidades Brasileiras - PAIUB.

tais: a não vinculação da avaliação com o financiamento e a adesão voluntária." (apud CATANI; OLIVEIRA, 2000, p. 10). O Paiub em sua fundamentação destacava que a avaliação deveria atender à tripla exigência da Universidade contemporânea: " a) um processo contínuo de aperfeiçoamento do desempenho acadêmico; b) uma ferramenta para o planejamento e gestão universitária; c) um processo sistemático de prestação de contas à sociedade." (PAIUB, 1993, p. 2). O Paiub citava ainda como princípios básicos: a) a aceitação ou conscientização da necessidade de avaliação por todos os segmentos envolvidos; b) reconhecimento da legitimidade e pertinência dos princípios norteadores e dos critérios a serem adotados; c) envolvimento direto de todos os segmentos da comunidade acadêmica na sua execução e na implementação de medidas para a melhoria do desempenho institucional.

O documento trazia ainda como objetivos específicos: a) impulsionar um processo criativo de autocrítica da instituição; b) conhecer, como se realizam e inter-relacionam o ensino, a pesquisa, a extensão e a administração; c) (re) estabelecer compromissos com a sociedade; d) repensar objetivos, modos de atuação e resultados na perspectiva de uma universidade mais consentânea com o momento histórico. Neste contexto,

O mérito do PAIUB é evidente, ao ter propiciado, acima de tudo um intercâmbio considerável de informações entre as universidades, aproximando-as em programas e preocupações comuns, favorecendo a identificação de problemas cruciais, percebidos como recorrentes no conjunto das universidades, sejam estas mantidas pelo Estado ou não. Alguns desses claros problemas residem: na precariedade de muitos sistemas de informação das universidades (são pouquíssimas as instituições bem estruturadas nesse setor); e na falta de clareza quanto aos objetivos primordiais a serem atingidos com a Avaliação Institucional - "o que fazer com isso tudo?" -, ao lado, ainda, de um grande desconhecimento quanto ao entendimento preciso do que é esse tipo de Avaliação (TRIGUEIRO, 1999, p. 38).

No Brasil havia certa aversão à avaliação institucional, uma vez que ela sempre fora conduzida com características externas e intervencionistas. Assim, Trindade (1996) defendia um programa de avaliação institucional negociado e discutido, o que foi acolhido pelo MEC e pela Andifes na elaboração do Paiub, colaborando para a redução da resistência ao programa.

Leite (2000) em seu estudo intitulado 'Inovação e avaliação: impacto e mudança' apresentou conclusões sobre a influência do Paiub em quatro universidades: uma federal, uma estadual, uma confessional privada e uma comunitária. Através de seus relatos pode-se conhecer a relevância ao Paiub para o cenário da universidade brasileira, em especial no que diz respeito à avaliação institucional.

Leite (2000) ao analisar o papel do Paiub no contexto das universidade pesquisadas destacou: "O processo de avaliação implantado, através do Paiub, foi feliz nesse sentido. Trabalhou de forma lenta e gradual, com firmeza, apoio político, e foi desvendando a instituição sem causar receios, sem ameaças ou punições." (p. 140). Ao concluir seu estudo, Leite (2000) destacou que as IES ao implementarem seus programas de avaliação institucional vinculados ao Paiub inovaram em seus processos através do paradigma emancipatório. Destacase ainda estarem todos centrados no pilar pedagógico que sustenta a universidade.

Em geral, esses processos não refletiram uma avaliação 'desinteressada' ou 'laissezfairre'como muitos manifestaram que o modelo PAIUB poderia sugerir. Refletiram as práticas 
sociais e culturais das comunidades acadêmicas, através da participação dos docentes dos diferentes saberes (professores, técnico-administrativos e alunos). (p. 145).

A proposta do Paiub não era o modelo que interessava ao Estado comprometido com acordos junto ao Banco Mundial, daí certamente o seu enfraquecimento nos anos subsequentes, muito embora a semente plantada germinou em inúmeras I.E.S.

A avaliação institucional, realizada pelo Paiub, foi reformulada para se adequar ao sistema de avaliação previsto pelo Decreto $n^{\circ} 2.026 / 96$, passando a responder pela avaliação do desempenho individual das instituições de ensino superior. Na medida em que se consolidasse, o Paiub deveria incorporar os resultados dos demais processos de avaliação implementados pelo MEC, integrando-os a num processo de contínuo aperfeiçoamento e de desenvolvimento da educação superior. Através da Portaria n ${ }^{0} 302$ de 07 de abril de 1998, o Ministério da Educação estabeleceu que a avaliação do desempenho individual das instituições de ensino, pesquisa e extensão seria realizada pela Secretaria de Educação Superior - SESu, no âmbito do Paiub.

A emergência de outras modalidades avaliativas, como o ENC e a Comissão de Especialistas deixou o Paiub em marcha lenta em que "muitos docentes e outros tantos discentes e técnicos, parecem amordaçados, aceitando os processos como se estivessem fora deles, distantes. Parece haver uma ausência de crítica e um esquecimento da história" (LEITE, 2000, p. 146).

A existência de um projeto institucional serviu de 'norte' para a efetivação do Paiub, de sua missão, dos seus objetivos e metas, e condição sine qua non para a autêntica avaliação institucional. O projeto institucional, na medida em que assumiu o papel de orientador das ações institucionais, direcionou as ações avaliativas sobre a I.E.S.. Neste sentido, o Paiub, notadamente, apresentou-se como o contexto mais propício ao desenvolvimento de atividades autoavaliativas por I.E.S. Atividades avaliativas isoladas, sem a devida contextualização e direcionamento, dificilmente representariam um movimento participativo e construtivo de uma cultura de avaliação global.

\subsection{O Paiub nas instituições de ensino superior fundacionais municipais catarinenses}

O ensino superior surgiu em Santa Catarina em 1917, com a criação do Instituto Politécnico, fechando em 1935, motivado por crise financeira. Em 1932, foi criada a Faculdade de Direito. No ano de 1960, foi criada a Universidade Federal de Santa Catarina - UFSC e em 1965, a Universidade para o Desenvolvimento do Estado de Santa Catarina - UDESC, ambas sediadas na capital, Florianópolis. A década de 1960 foi marcada pela expansão do ensino superior catarinense, com a autorização pelo Conselho Estadual de Educação dos primeiros cursos, cuja instalação contribuiu para o processo de interiorização do mesmo. Independente da ação do governo federal ou estadual, fundações educacionais foram sendo criadas, com estruturas administrativas e financeiras próprias - em todos os casos com o aval dos municípios - públicas, portanto - com forte apoio financeiro. Nas décadas de 1960 e 1970, havia sido criadas dezoito fundações educacionais pelas prefeituras municipais. A inclusão das IES fundacionais catarinenses, no Sistema Estadual de Educação, remonta à lei federal n. 4.024/61. Com a promulgação da lei federal n. 9.394/96, o Conselho Estadual de Educação lançou mão da Resolução n. 03/97, baseando-se no artigo 242, da Constituição da República 
Os impactos e mudanças promovidos pela avaliação institucional no ensino de graduação das instituições de ensino superior fundacionais municipais catarinenses sob influência do Programa de Avaliação Institucional das Universidades Brasileiras - PAIUB.

Federativa do Brasil, enquadrando as IES no inciso II, do artigo 17 da citada lei, chamando para si a gestão do ensino superior fundacional catarinense. A criação das IES, por lei municipal, não representou necessariamente a manutenção das mesmas pelo poder público. A partir da Constituição de 1988 (BRASIL, 1988), os municípios passam a atuar prioritariamente no ensino fundamental, debilitando as fundações municipais. A partir da década de 1980, as IES transformaram-se em universidades, sejam individualmente, sejam via união de várias fundações. O sistema das IES municipais catarinenses cobre todo o estado de Santa Catarina, envolvendo uma comunidade superior a cem mil pessoas, entre alunos, professores e técnicos.

Ao se falar de universidade, não se pode deixar de ter claro as especificidades de cada instituição. Apesar da legislação estabelecer algumas regras para estruturação das mesmas, o caráter regional acaba moldando a face da universidade. Assim, "quando se fala de Universidade, é mais adequado o sentido de 'Universidades', o plural como indicador das diferenças e da diversidade das instituições universitárias, entendidas como produção social, portanto, históricas, distintas e cambiantes (DIAS SOBRINHO, 1995, p. 16).

Influenciado pelo Paiub, em março de 1994 a Associação Catarinense das Fundações Educacionais - Acafe, entidade que agrega as IES, objeto desta pesquisa, lançou o Programa de Avaliação Institucional, de Desempenho Gerencial e Qualidade no Ensino, com vistas a promover atividades de avaliação que contribuíssem para a consolidação do sistema fundacional de ensino superior catarinense. O financiamento propiciado pelo Paiub foi um estimulador para a implementação dos primeiros programas nas IES. Com o passar do tempo todas iniciaram programas avaliativos.

A partir das visitas e entrevistas realizadas, constatou-se que todas as IESFMC desenvolveram, com maior ou menor efetividade, um programa de avaliação institucional. Afinal, este programa provocou impactos e mudanças no ensino de graduação das IES pesquisadas quando da sua implementação?

Após tratamento estatístico dos resultados obtidos pela quantificação dos valores atribuídos pelos entrevistados a quesitos das categorias avaliação (interna e externa), impactos e mudanças constante no anexo 01, considerando o somatório das etapas cumpridas, chegou-se ao seguinte quadro síntese:

Quadro 1 - Quadro síntese dos resultados avaliativos - Média CPAI e Proen

\begin{tabular}{|c|c|c|c|c|c|c|}
\hline \multirow{2}{*}{\multicolumn{2}{|c|}{ Instituição }} & \multicolumn{5}{|c|}{ Pontuações } \\
\hline & & \multicolumn{3}{|c|}{ Avaliação } & Impactos & \multirow{2}{*}{$\frac{\text { Mudanças }}{\text { Total }}$} \\
\hline N. & SIGLA & Interna & Externa & Total & Total & \\
\hline 01 & UNI-01 & 42 & - & 42 & 220 & 697 \\
\hline 02 & UNI-02 & 27 & - & 27 & 165,5 & 517,5 \\
\hline 03 & UNI-03 & 48 & 87 & 135 & 160,5 & 669,5 \\
\hline 04 & UNI-04 & 40 & - & 40 & 134,5 & 637,5 \\
\hline 05 & UNI-05 & 24 & - & 24 & 158 & 519 \\
\hline 06 & UNI-06 & 24 & - & 24 & 117,5 & 433 \\
\hline 07 & UNI-07 & 11 & - & 11 & 84,5 & 531 \\
\hline 08 & UNI-08 & 19 & - & 19 & 165 & 622,5 \\
\hline 09 & UNI-09 & 18 & - & 18 & 153 & 711,5 \\
\hline 10 & UNI-10 & 30 & - & 30 & 146,5 & 581,5 \\
\hline 11 & UNI-11 & 18 & - & 18 & 138 & 547 \\
\hline
\end{tabular}

Fonte: Dados da pesquisa 
O quadro síntese permitiu a construção dos gráficos que seguem:

\section{Gráfico 01 - Relação avaliação X impactos X mudanças}

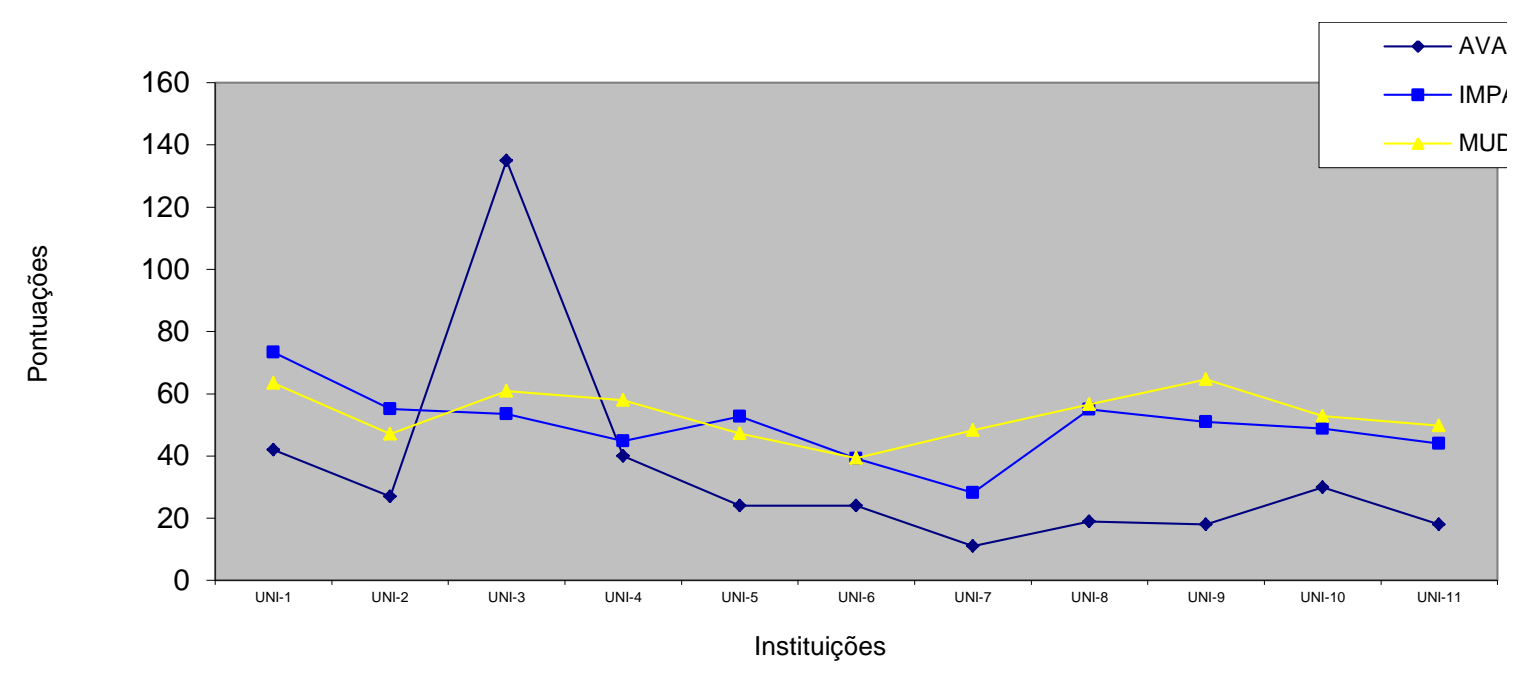

O gráfico permitiu constatar, a partir das percepções dos Pró-reitores de ensino e Coordenadores das Comissões de Avaliação Institucional, que as IES encontravam-se em estágios diferenciados quanto ao desenvolvimento das atividades de avaliação institucional. A UNI-03, pelo fato de já ter concluído a avaliação externa, era a que apresentava melhor desempenho. A UNI-07 era a que cumprira em menor percentual as etapas da avaliação interna.

Das onze IESFMC pesquisadas, a que apresentava maiores impactos e mudanças nas condições de produção do ensino de graduação foi a UNI-01. É compreensível o resultado obtido por esta IESFMC: foi a pioneira no PAIUB, dentre as IESFMC, obtendo financiamento já no primeiro edital do Paiub. Isso demonstrou a preocupação com a necessidade da avaliação institucional; disponibilizou recursos humanos e materiais para a implementação do processo. Todos os membros da comissão cursaram programa de especialização em avaliação institucional e os resultados foram publicizados em cadernos de acesso à comunidade universitária.

Quando analisada a relação avaliação X impacto, constatou-se que a avaliação gerou impactos em todas as IES, variando de intensidade em relação ao número de etapas da avaliação concluídas. Com os maiores impactos, em função da avaliação, foram apontados os da UNI-01 e UNI-08 e a menor da UNI-07. Esta classificação é coerente, quando se analisa o total de etapas da avaliação cumpridas: a UNI-07 foi a que cumpriu menor número e a UNI01 atingiu pontuação 42 de um total máximo de 52 pontos.

Chamou a atenção duas IES: a UNI-07 e a UNI-09. Ambas realizaram menos avaliação mas obtiveram grandes mudanças. Qual seria a explicação para tal fato? A percepção dos entrevistados recaiu sobre o período em que o programa foi implementado nas I.E.S., ou seja, na UNI-07 entre 1994 e 1997 e na UNI-09 entre 1998 e 2002. Neste período ambas implementaram as fases iniciais do programa e, em ambas, este deslanchar promoveu além de impactos também mudanças, pois as medidas e ações eram de fácil cumprimento. Evidentemente, se tivessem cumprido a maioria das etapas, a exemplo da UNI-01 e UNI-03, como muitas 
Os impactos e mudanças promovidos pela avaliação institucional no ensino de graduação das instituições de ensino superior fundacionais municipais catarinenses sob influência do Programa de Avaliação Institucional das Universidades Brasileiras - PAIUB.

delas demandam maiores investimentos para a sua concretização, os resultados poderiam indicar que as mudanças quando diluídas ao longo do tempo seriam menores, mas presentes. Uma variável que também influenciou as I.E.S. era no fato de ambas terem passado por processo de credenciamento para obtenção da condição de Universidade o que pode ter contribuído para que as mudanças ocorressem num curto espaço de tempo.

Há de se esclarecer, entretanto, que por ocasião da coleta dos dados o pesquisador frisou junto aos entrevistados que as respostas quanto aos impactos e mudanças fossem vinculados exclusivamente como decorrência da implementação do Paiub desconsiderando-se mudanças e impactos gerados pelo então Exame Nacional de Cursos - ENC, por exemplo.

Segundo a percepção dos CPAI e Proen, os maiores impactos recaíram, por ordem de média na: preocupação com a melhoria da qualidade dos cursos; identificação dos pontos fracos da IES; disponibilização dos resultados aos docentes; disposição para o diálogo por parte da administração central; discussão do projeto pedagógico.

Porém, os menores impactos, por ordem de média recaíram na: concessão de bolsas para estudantes; cursos sobre avaliação institucional; construção da síntese diagnóstica do conjunto da IES; organização de seminários; palestras sobre avaliação institucional.

Quando analisada a relação avaliação X mudança, constatou-se também que em todas as IES a mudança fizera-se presente, variando de intensidade. As IESFMC que apresentaram maior índice de mudança atribuída à avaliação institucional foram a UNI-01, a UNI-03 e a UNI-09 Dentre as que apresentaram menor índice, por ordem, estão: a UNI-06, UNI-11, UNI07 e UNI-10 e a UNI-02.

Analisando-se comparativamente, as IESFMC que concluíram maior número de etapas apresentaram melhor desempenho e vice-versa , o que nos levou a inferir que a medida em que o programa foi avançando, as transformações tornaram-se mais evidentes. Das dezessete etapas objeto de avaliação interna: a UNI-01 cumpriu quinze e a UNI-03 dezesseis. Enquanto, por exemplo, a UNI-07 foi a que cumpriu menor número de etapas, apenas seis. Pode-se atribuir o reduzido número de etapas cumpridas pelos programas de avaliação institucional nas IESFMC, UNI-06 e UNI-07 à própria forma de organização. Elas são multicampi, fruto da aglutinação de fundações isoladas, diferentemente do que ocorre com as demais, em que uma única fundação deu origem a uma universidade. A dificuldade residiu no fato de cada campi possuir certa autonomia administrativa. A condição de universidade ainda não permitiu a superação, ou seja, uma unidade administrativa total. À medida que cada uma possui autonomia, fica a critério dos gestores de cada campi assumir a avaliação como um programa prioritário ou não. Há nestas instituições variação entre cada campi: alguns com programas avaliativos mais consolidados, outros menos, o que na média as coloca numa posição de pouco destaque.

Segundo a percepção dos coordenadores e pró-reitores de ensino, as maiores mudanças residem, por ordem de média na(o): Projeto Político Pedagógico; Infraestrutura; Gestão e Administração; Corpo docente; Currículo; Relação Universidade/sociedade; Corpo discente; Extensão; Pesquisa.

As mudanças percebidas justificam-se na medida em que as etapas de avaliação concluídas estão diretamente vinculadas. Por exemplo: todas as IESFMC concluíram as etapas de sensibilização, diagnóstico, avaliação do corpo docente, das disciplinas e da infraestrutura. 
A extensão, a pesquisa, a interação com a comunidade externa, a estrutura curricular, o perfil profissional e as perspectivas de mercado de trabalho, por ordem, foram as condições menos avaliadas internamente pelas IESFMC. Logo, justificou-se que a pesquisa e a extensão eram as condições que apresentaram pouca mudança. Por outro lado, causava preocupação o fato de o projeto político pedagógico ter sido indicado como a variável que sofreu maior mudança, uma vez que condições essenciais para se discuti-lo ainda não foram avaliadas na totalidade das IESFMC, como por exemplo, a estrutura curricular, o perfil profissional e as perspectivas de mercado de trabalho.

Ao analisar o gráfico 01, o qual apresenta a relação avaliação X impacto X mudança, algumas considerações mereceram destaque. Chamou a atenção o fato da UNI-01 e UNI-02 apresentarem impactos maiores que as mudanças. Considerando como IES que há mais tempo desenvolveram trabalhos avaliativos, pode-se inferir que à medida que o programa foi se consolidando, as mudanças tornaram-se menos perceptíveis, ou seja, passaram a fazer parte do cotidiano da IES. Outra situação estava presente na UNI-07, cujo número de etapas cumpridas é bastante reduzido. Entretanto, as mudanças são percebidas com maior evidência. A explicação está no fato desta IES, ao ter cumprido poucas etapas do processo avaliativo, gerou de imediato mudanças significativas. Esta percepção representava a IES no momento em que o programa era implementado.

Quando das entrevistas, procurou-se identificar a intensidade das mudanças, utilizando-se uma escala ordinal de cinco pontos (nenhum, pequeno, médio, grande, muito grande). $\mathrm{O}$ gráfico seguinte permite uma melhor visualização das mudanças nas condições propostas:

\section{Gráfico 02 - Grau de intensidade das mudanças percebidas}

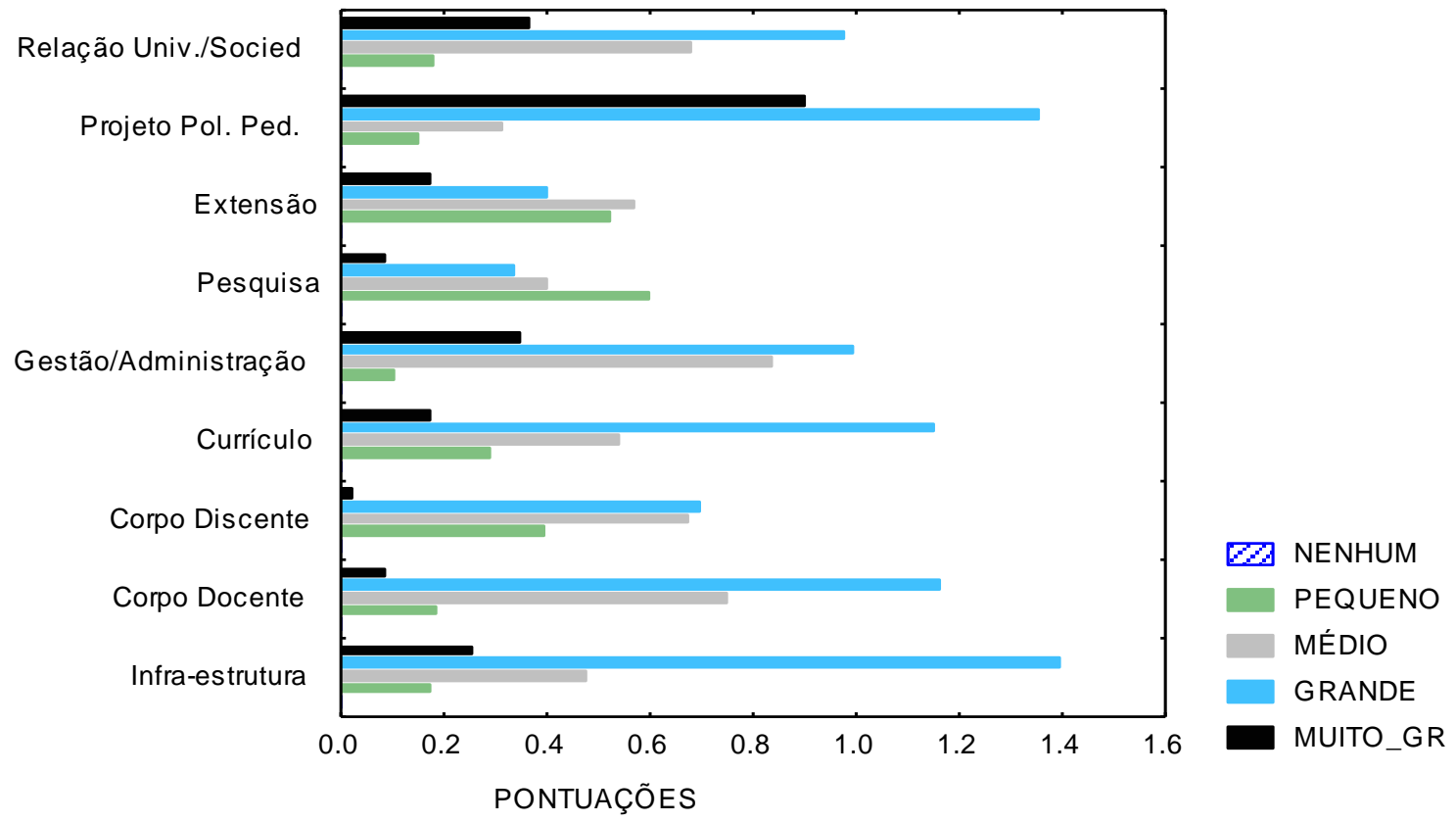

Analisando individualmente cada condição avaliada, algumas observações mereceram destaque: quanto ao Projeto Político Pedagógico a mudança mais significativa recaiu na elaboração do mesmo pelos cursos; na infraestrutura as mudanças recaem na ampliação e melhoria do acervo bibliográfico, na melhoria das salas de aula e na ampliação do número de labo- 
Os impactos e mudanças promovidos pela avaliação institucional no ensino de graduação das instituições de ensino superior fundacionais municipais catarinenses sob influência do Programa de Avaliação Institucional das Universidades Brasileiras - PAIUB.

ratórios; - quanto ao corpo discente, as mudanças percebidas foram menores, destacando-se a participação na tomada de decisões e o comprometimento com o curso, entretanto a participação dos discentes em atividades de ensino e pesquisa sofreram poucas mudanças com a avaliação institucional; quanto ao currículo, as mudanças foram direcionadas muito mais ao mercado que ao conhecimento social. Esta tendência entra em conflito com os princípios do Paiub, os quais preconizavam uma avaliação que promovesse mudanças e oportunizasse a emancipação. No corpo docente, as maiores mudanças foram percebidas na melhoria da qualificação docente, no comprometimento com o curso e no melhor desempenho didáticopedagógico.

Ainda, no que tange ao corpo docente, as menores mudanças foram percebidas na ampliação da carga horária; no reduzido envolvimento em atividades de pesquisa e extensão e na pouca participação nas atividades colegiadas.

A condição de professor que não se dedicava integralmente à IES, em termos de carga horária, ainda que aquela realidade tenha sofrido mudanças suscitava preocupações, pois $79,9 \%$ dos docentes encontravam-se nesta condição no período pesquisado. O fato dos docentes não vivenciarem a universidade na sua integralidade acabou prejudicando não apenas o envolvimento na pesquisa e na extensão, mas também na avaliação institucional. No campo da avaliação o prejuízo se fez presente uma vez que o professor acabou não participando ativamente do processo. A pesquisa permitiu conhecer que o grau de aceitação do projeto de avaliação por parte dos professores foi expresso como médio. A UNI-01, que se destacou ao apresentar bom desempenho no processo de avaliação, foi uma das I.E.S. com maior percentual de professores em tempo integral, ou seja 32,2\% que somado aos 36,4\% de tempo parcial compõem um quadro de $68,6 \%$ dos docentes com maior dedicação à I.E.S. A UNI-01 foi também a I.E.S. que possuía docentes com melhor titulação. Logo, maior dedicação e melhor titulação aliado a um programa contínuo de avaliação geraram resultados. A maior presença na I.E.S. permitiu participação ativa nos colegiados, onde via de regra os resultados das avaliações são discutidas, o projeto político pedagógico do curso foi reformulado em função da mesma. Acreditava-se que daquela forma poderia se superar o silêncio docente frente à avaliação.

De certo modo, isso pode justificar a reduzida mudança proporcionada pela Avaliação Institucional nas atividades de extensão e pesquisa. A pouca disponibilidade de docentes para tais atividades nas IES traz como consequência a reduzida produção científica e de extensão. Logo, não havendo docentes envolvidos nestas ações, também os discentes não encontram ambiente e estímulo para tais práticas.

No campo da gestão e administração, as maiores mudanças apontaram para a transparência nas decisões, ficando em segundo plano a colegiabilidade das decisões. Aliás, coerente as posições, na medida em que tanto entre discentes como entre docentes a participação nos colegiados não sofreu mudança significativa, efeito provável do modelo de gestão das estruturas superiores. 
Gráfico 03 - Grau de intensidade das mudanças percebidas por IESFMC e categoria

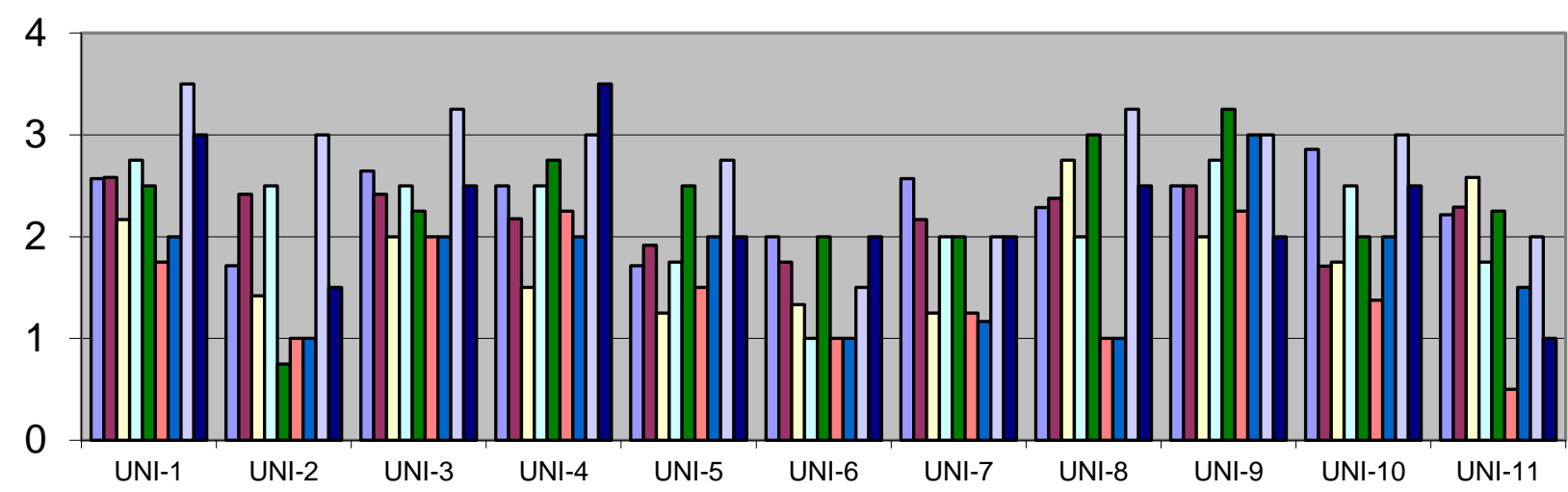

\begin{tabular}{|c|c|c|}
\hline 口Infra-estrutura & 口Corpo Docente & 口Corpo Discente \\
\hline 口Currículo & 口Gestão e Administração & 口Pesquisa \\
\hline 口Extensão & 口Projeto Político Pedagógico & - Relação Universidade/sociedade \\
\hline
\end{tabular}

Quando analisado o grau de intensidade das mudanças percebidas por IESFMC e por categoria, a UNI-10 apresentou a maior mudança, no campo da infraestrutura; a UNI-01 apresentou a maior mudança, no corpo docente, no currículo e no projeto político pedagógico; a UNI-08 no corpo discente; a UNI-09 na gestão e administração, na pesquisa e na extensão; a UNI-04 na pesquisa e relação universidade e sociedade.

Quando analisadas as IESFMC com menores mudanças percebidas, destacaram-se: a UNI-06 na infraestrutura, no currículo, na extensão e projeto político pedagógico; a UNI-10 no corpo docente; a UNI-05 e a UNI-07 no corpo discente; a UNI-02 na gestão e administração, na extensão; a UNI-11 na pesquisa e na relação universidade e sociedade; a UNI-08 na extensão.

Considerando que cada instituição apresentou níveis diferentes de desenvolvimento da avaliação, impactos e mudanças, além de não desenvolver uniformemente as três variáveis observadas, tornou-se interessante realizar uma tentativa de reunir as instituições em grupos que apresentaram alguma similaridade. O procedimento geralmente adotado é a utilização da análise multivariada, mais precisamente por meio de um estudo de análise de agrupamento (Cluster). Segundo Pereira (1999), neste tipo de análise as distâncias entre objetos estudados são calculados e, a seguir, os objetos são agrupados conforme a proximidade entre eles.

Por um procedimento de análise multivariada, mais precisamente, a análise de Cluster, estudou-se as IESFMC com relação as variáveis: avaliação, impacto e mudança a fim de verificar quais as que estavam mais próximas em relação às variáveis, a partir da percepção dos CPAI e Proen. Este procedimento situa num mesmo grupo as IESFMC que apresentaram níveis semelhantes, quanto as três variáveis. 


\section{Gráfico 04 - Distribuição das IES segundo os agrupamentos realizados}

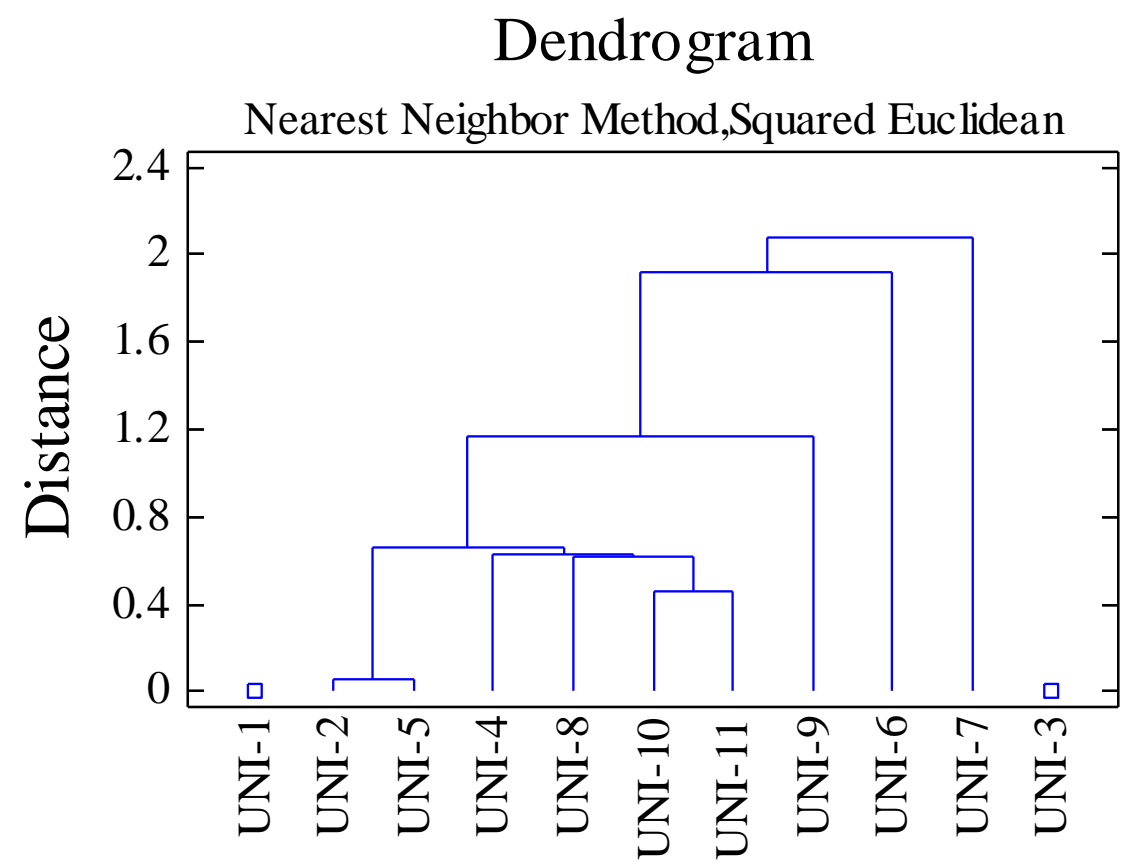

Tabela 01 - Distribuição das IESFMC segundo os agrupamentos realizados

\begin{tabular}{c|c|c|c|c}
\hline \multirow{2}{*}{ Grupos } & Instituições & \multicolumn{3}{|c}{ Centróides } \\
\cline { 3 - 5 } & & Avaliação & Impacto & Mudança \\
\hline 1 & UNI-1 & 42,0 & 220,0 & 697,0 \\
2 & UNI-2, UNI-5, UNI-10, UNI-8, UNI-9, UNI- & & & \\
& 11, UNI-6, UNI-4, UNI-7 & 23,4 & 140,2 & 566,7 \\
3 & UNI-3 & 135,0 & 160,5 & 669,5 \\
\hline
\end{tabular}

Fonte: Gráfico elaborado a partir de informações obtidas em entrevista junto aos CPAI e Proen das IESFMC.

Observa-se que as instituições UNI-3 e UNI-1 apareceram isoladas das demais, não se agrupando. Já as instituições UNI-2, UNI-5, UNI-10, UNI-07, UNI-8, UNI-9, UNI-11, UNI-6 e UNI-4 apareceram num agrupamento homogêneo, mostrando que as variáveis avaliação, impactos e mudanças são muito semelhantes ou próximas. O maior distanciamento entre as IES UNI-01 e UNI-03 pode ser atribuído ao fato da primeira ter sido a precursora dos programas de avaliação institucional, gerando um programa mais consolidado. No entanto, à segunda atribuiu-se o distanciamento pelo fato de ter sido a única IES a ter concluído a avaliação externa.

As demais apresentam uma proximidade no desenvolvimento das ações avaliativas no que tange aos impactos e mudanças proporcionados pelos programas de avaliação institucional.

\section{Considerações finais}


A guisa de conclusão, quanto aos impactos e mudanças promovidos pela avaliação institucional nas IES fundacionais municipais catarinenses sob influência do Paiub, pode-se afirmar: todas desenvolveram com maior ou menor intensidade atividades de avaliação institucional; os maiores impactos recaíram na preocupação com a melhoria da qualidade de ensino na graduação motivadas pelo Paiub; o menor impacto foi percebido na concessão de bolsa de estudos para estudantes; as mudanças mais intensas percebidas recaem na elaboração do projeto político pedagógico e na melhoria das condições de infraestrutura; as mudanças menos perceptíveis estavam nas condições de pesquisa e extensão, o que se deve à falta de tradição das IES e também ao fato da avaliação não ter privilegiado até a presente data ambas; quanto ao corpo docente, as mudanças mais significativas estavam na melhoria da qualificação profissional, sendo que ainda em muitas IES a titulação era deficitária e um percentual significativo dos docentes atuam em tempo parcial ou são horistas. A avaliação não havia promovido mudanças significativas na colegiabilidade das decisões; percebeu-se certo equilíbrio entre as IES quanto às variáveis avaliação, impacto e mudança.

\section{Referências}

BRASIL. Constituição da República Federativa do Brasil. Brasília: MEC, 1988.

BRASIL. MEC. Programa Nacional de Avaliação das Universidade Brasileira - Paiub. Brasília, 1993

CATANI, A. M.; OLIVEIRA, J. F. de. O sistema e a política de avaliação da educação superior no Brasil. R.A.I.E.S., Campinas, n. 17, p. 10, set. 2000.

DIAS SOBRINHO, J. Avaliação da educação superior. Petrópolis: Vozes, 2000.

DIAS SOBRINHO, J. Universidade: processos de socialização e processos pedagógicos. In: BALZAN, N. C., DIAS SOBRINHO, J. (Orgs.). Avaliação institucional: teoria e experiências. São Paulo: Cortez, 1995. p. 15-35.

FREITAS, I. M. A.C.; SILVEIRA, A. Avaliação da educação superior. Florianópolis: Insular, 1997.

LEITE, D. Inovação como fator de revitalização do ensinar e do aprender na universidade. O caso da avaliação institucional. Estudo desenvolvido por grupos interinstitucionais de pesquisa. Porto Alegre: Editora e Gráfica Universitária Ufpel, 2000.

MARCHI, E. PAIUB: a experiência da região sul. Avaliação, Campinas, n. 2, p. 53-4, dez. 1996.

PEREIRA, J. C. R. P. Análise de dados qualitativos: estratégias metodológicas para as ciências da saúde, humanas e sociais. São Paulo: Edusp, 1999.

RISTOFF, D. I. Universidade em foco: reflexões sobre a educação superior. Florianópolis: Insular, 1999.

SINDER, Marilene. Avaliação institucional: o desafio da universidade brasileira na superação da crise da modernidade. Niterói, 1998. Dissertação. (Mestrado em Educação) - 
Os impactos e mudanças promovidos pela avaliação institucional no ensino de graduação das instituições de ensino superior fundacionais municipais catarinenses sob influência do Programa de Avaliação Institucional das Universidades Brasileiras - PAIUB.

Programa de Pós-Graduação em Educação, Centro de Estudos Sociais Aplicados, Universidade Federal Fluminense, 1998.

TRIGUEIRO, Michelangelo Giotto Santoro. A avaliação institucional nas universidades brasileiras: diagnóstico e perspectivas. Estudos e Debates, Brasília, n. 20, p. 37-109. Mar.1999.

TRINDADE, H. Universidade em perspectiva. Porto Alegre: UFRS, 1996.

Argos Gumbowsky - Universidade do Contestado Canoinhas | SC | Brasil. Contato: argosgum@gmail.com 


\section{ANEXO 01}

Quadro referência de valores para as etapas possíveis de serem alcançados nas I.E.S. e suas respectivas pontuações.

\begin{tabular}{|c|c|c|c|}
\hline \multicolumn{4}{|c|}{ Avaliação do ensino de graduação } \\
\hline AVALIAÇÃO INTERNA & $P$ & AVALIAÇÃO EXTERNA & $P$ \\
\hline Programa de sensibilização & 1 & Estrutura curricular & 9 \\
\hline Realização do diagnóstico & 1 & Disciplinas & 7 \\
\hline Estrutura curricular & 4 & Corpo docente & 7 \\
\hline Disciplinas & 2 & Corpo discente & 8 \\
\hline Corpo docente & 2 & Corpo técnico-administrativo & 7 \\
\hline Corpo discente & 3 & Gestão & 7 \\
\hline Corpo técnico administrativo & 2 & Infra estrutura & 6 \\
\hline Perfil profissional & 4 & Avaliação de egressos ou concluintes & 10 \\
\hline Gestão & 2 & Pesquisa & 8 \\
\hline Infraestrutura & 2 & Extensão & 8 \\
\hline Avaliação de egressos ou concluintes & 5 & Mercado de trabalho & 10 \\
\hline Extensão & 3 & IMPACTOS & $\mathrm{P}$ \\
\hline Pesquisa & 3 & Concessão de bolsas para estudantes & 1 \\
\hline Interação com a comunidade interna & 4 & Elaboração de relatórios & 2 \\
\hline Interação com a comunidade externa & 5 & Publicações de relatórios & 3 \\
\hline Atratividade do curso & 4 & Palestras sobre avaliação institucional & 1 \\
\hline MUDANÇAS & $P$ & Organização de seminários & 4 \\
\hline Perspectivas de mercado de trabalho & 5 & Cursos sobre avaliação institucional & 2 \\
\hline Infraestrutura & 6 & Identificação dos pontos fracos da IES & 5 \\
\hline Corpo docente & 7 & Implementação de novo projeto & 5 \\
\hline Corpo discente & 6 & Disponibilização dos resultados aos docentes & 3 \\
\hline Currículo & 10 & Disponibilização dos resultados aos discentes & 3 \\
\hline Gestão e administração & 7 & $\begin{array}{l}\text { Disposição para o diálogo por parte da administração } \\
\text { central }\end{array}$ & 3 \\
\hline Pesquisa & 8 & Preocupação com a melhoria da qualidade dos cursos & 1 \\
\hline Extensão & 8 & Discussão do projeto pedagógico & 2 \\
\hline Projeto político pedagógico & 10 & Divulgação dos resultados da avaliação & 3 \\
\hline \multirow[t]{4}{*}{ Relação Universidade/Sociedade } & 10 & Divulgação das ações da avaliação & 3 \\
\hline & & Repensar do curso & 5 \\
\hline & & $\begin{array}{l}\text { Construção da síntese diagnóstica do conjunto da } \\
\text { I.E.S. }\end{array}$ & 5 \\
\hline & & Publicização do resultado da avaliação & 3 \\
\hline
\end{tabular}

Fonte: Quadro organizado a partir de LEITE (2000)

$\mathrm{P}=$ Ponto 